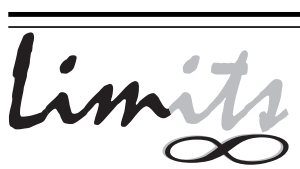

J. Math. and Its Appl.

ISSN : $1829-605 \mathrm{X}$

Vol. 4, No. 2, November 2007, 1-8

\title{
REDUKSI RANK PADA MATRIKS-MATRIKS TERTENTU
}

\author{
Erna Apriliani ${ }^{1}$, Bandung Arry Sanjoyo \\ ${ }^{1}$ Jurusan Matematika \\ FMIPA Institut Teknologi Sepuluh Nopember, Surabaya \\ ${ }^{1}$ april@matematika.its.ac.id
}

\begin{abstract}
Abstrak
Dekomposisi nilai singular (Singular Value Decomposition - SVD) adalah suatu metode untuk menuliskan suatu matriks dalam bentuk perkalian antara matriks diagonal yang berisi nilai-nilai singularnya $(D)$, dengan matriks yang berisi vektor-vektor singular yang bersesuaian $(U$ dan $V)$. Suatu matriks setelah dituliskan dalam matriks diagonal nilai singular dan matriks vektor singularnya dapat dilakukan reduksi rank pada matriks diagonal nilai singularnya. Reduksi rank ini bermanfaat untuk mengurangi waktu komputasi suatu algoritma yang membutuhkan perkalian matriks. Pada penelitian ini akan dilakukan reduksi rank untuk beberapa matriks tertentu. Matriks $A$ yang dikaji berupa matriks diagonal, matriks tridiagonal dan full matriks. Akan dikaji kaitan antara reduksi rank dan tingkat akurasi penyelesaian serta waktu komputasi. Simulasi dilakukan dengan bantuan Matlab.

Katakunci: Reduksi rank, dekomposisi nilai singular, sistem persamaan linear
\end{abstract}




\section{Pendahuluan}

Perkalian dua buah matriks atau lebih sering sekali dilakukan pada penyelesaian masalah-masalah dalam bidang matematika maupun penerapan matematika. Untuk matriks ukuran besar, perkalian matriks membutuhkan waktu komputasi yang cukup lama. Oleh karena itu perlu suatu metode untuk mengurangi waktu komputasi tersebut, salah satunya dengan melakukan reduksi rank suatu matriks yang telah didekomposisi.

Dekomposisi nilai singular (Singular Value Decomposition-SVD) merupakan metode dekomposisi yang sering dilakukan. Pada metode ini suatu matriks dituliskan dalam bentuk perkalian antara matriks diagonal yang berisi nilai-nilai singularnya $(D)$, dengan matriks yang berisi vektor-vektor singular yang bersesuaian $(U$ dan $V$ ). Reduksi rank dilakukan pada matriks diagonal nilai singularnya. Reduksi rank ini bermanfaat untuk mengurangi waktu komputasi suatu algoritma yang membutuhkan perkalian matriks.

Pada penelitian ini dilakukan reduksi rank untuk beberapa matriks tertentu. Matriks $A$ yang dikaji berupa matriks diagonal, matriks tridiagonal. Pada paper ini dikaji kaitan antara reduksi rank dan tingkat akurasi penyelesaian serta waktu komputasi. Simulasi dilakukan dengan bantuan Matlab. Sedangkan penerapan reduksi rank pada sistem persamaan linear belum dapat dilakukan, masih memerlukan kajian lebih lanjut.

\section{Dekomposisi Nilai Singular}

Keberadaan dari dekomposisi nilai singular (Singular Value DecompositionSVD) suatu matriks dinyatakan oleh teorema berikut.

Teorema 2.1 Jika $A_{m \times n}$ suatu matriks real maka terdapat matriksmatriks ortogonal

$$
U=\left[u_{1}, \ldots, u_{m}\right] \in \mathbb{R}^{m \times m}
$$

dan

$$
V=\left[v_{1}, \ldots, v_{n}\right] \in \mathbb{R}^{n \times n}
$$

sedemikian hingga

$$
U^{T} A V=\operatorname{diag}\left(\sigma_{1}, \ldots, \sigma_{p}\right) \in \mathbb{R}^{m \times n}
$$


dengan $p=\min \{m, n\}$, dan $\sigma_{1} \geq \sigma_{2} \geq \ldots \geq \sigma_{p} \geq 0$ adalah nilai-nilai singular matriks $A$

Teorema tersebut juga menyatakan bahwa matriks $A_{m \times n}$ dapat dinyatakan sebagai dekomposisi matriks yaitu matriks $U, D$ dan $V$. Matriks $D$ merupakan matriks diagonal dengan elemen diagonalnya berupa nilai-nilai singular matriks $A$, sedangkan matriks $U$ dan $V$ merupakan matriks-matriks yang kolom-kolomnya berupa vektor singular kiri dan vektor singular kanan dari matriks $A$ untuk nilai singular yang bersesuaian.

\section{Reduksi Rank Suatu Matriks}

Reduksi rank merupakan salah satu cara untuk mengurangi waktu komputasi suatu perkalian matriks. Misalkan diberikan matriks real $A_{m \times n}$, reduksi rank dari matriks tersebut dapat dilakukan dengan cara berikut:

1. Lakukan dekomposisi nilai singular dari matriks $A$ yaitu $[U, D, V]=$ $\operatorname{svd}(A)$, artinya $A=U D V^{T}$, dengan $D$ adalah matriks diagonal yang berisi nilai singular dari matriks $A$, sedangkan $U, V$ matriks-matriks yang berisi vektor-vektor singular dari $A$ yang berkaitan dengan nilai singularnya.

2. Reduksi rank dilakukan pada matriks diagonal $D$. Misalnya matriks $D^{*}$ berukuran $q \times q$ adalah reduksi dari matriks $D$, didefinisikan $D^{*}=$ $D(1: q, 1: q)$ dengan $q<\min \{n, m\}$. Matriks $A^{*}=U^{*} D^{*}\left(V^{*}\right)^{T}$ merupakan matriks reduksi rank dari matriks $A$. Misalkan

$$
D=\left(\begin{array}{ccccc}
\sigma_{1} & 0 & \ldots & 0 & 0 \\
0 & \sigma_{2} & 0 & \ldots & 0 \\
. & . & . & \ldots & . \\
. & . & \ldots & \sigma_{q} & . \\
. & . & . & \ldots & \sigma_{p} \\
0 & 0 & \ldots & 0 & 0
\end{array}\right)
$$




$$
\begin{aligned}
& \text { dengan } \sigma_{1} \geq \sigma_{2} \geq \ldots \geq \sigma_{q} \geq \ldots \geq \sigma_{p} \geq 0 \text {, maka } \\
& D_{q \times q}^{*}=\left(\begin{array}{ccccc}
\sigma_{1} & 0 & \ldots & 0 & 0 \\
0 & \sigma_{2} & 0 & \ldots & 0 \\
\cdot & . & . & \ldots & . \\
. & . & \ldots & . & . \\
. & . & . & \ldots & . \\
0 & 0 & \ldots & 0 & \sigma_{q}
\end{array}\right) \\
& U_{m \times q}^{*}=\left(\begin{array}{ccccc}
u_{1}^{1} & u_{2}^{1} & \ldots & u_{q-1}^{1} & u_{q}^{1} \\
u_{1}^{2} & u_{2}^{2} & \ldots & u_{q-1}^{2} & u_{q}^{2} \\
\cdot & \cdot & \ldots & \cdot & \cdot \\
\cdot & \cdot & \ldots & \cdot & \cdot \\
\cdot & \cdot & \ldots & \cdot & \cdot \\
u_{1}^{m} & u_{2}^{m} & \ldots & u_{q-1}^{m} & u_{q}^{m}
\end{array}\right) \\
& V_{m \times q}^{*}=\left(\begin{array}{ccccc}
v_{1}^{1} & v_{2}^{1} & \ldots & v_{q-1}^{1} & v_{q}^{1} \\
v_{1}^{2} & v_{2}^{2} & \ldots & v_{q-1}^{2} & v_{q}^{2} \\
\cdot & \cdot & \ldots & \cdot & \cdot \\
\cdot & \cdot & \ldots & \cdot & \cdot \\
\cdot & \cdot & \ldots & \cdot & \cdot \\
v_{1}^{m} & v_{2}^{m} & \ldots & v_{q-1}^{m} & v_{q}^{m}
\end{array}\right)
\end{aligned}
$$

Sehingga matriks $A^{*}$ merupakan matriks yang berukuran $m \times n$ dengan rank $q$.

Pada [1] telah ditunjukkan norm selisih dari matriks tereduksi dan matriks awalnya sebagaimana teorema berikut:

Teorema 3.1 Misalkan diberikan $[U, D, V]=\operatorname{svd}(A)$. Jika $k<n=$ $\operatorname{rank}(A)$ dan $A_{k}=\sum_{i=1}^{k} \sigma_{i} u_{i} v_{i}^{T} \operatorname{maka}\left\|A-A_{k}\right\|=\sigma_{k+1}$.

Pada penelitian ini didefinisikan, suatu matriks dikatakan dapat direduksi jika matriks tereduksi tersebut mempunyai rank $q$, dengan $q<$ $\frac{2}{3} \min \{m, n\}$ dan $\frac{\left\|A^{*}-A\right\|}{\|A\|}<0.1$.

Selajutnya akan dilakukan simulasi reduksi rank dari matriks diagonal, matriks tridiagonal dan full matriks dengan entri-entri berupa bilangan random. 


\section{Hasil Simulasi dan Pembahasan}

Telah dilakukan simulasi reduksi rank untuk matriks-matriks dengan elemen penuh (full matrix), matriks diagonal, matriks tridiagonal, baik tridiagonal random, simetri dan elemen diagonal nol.

Simulasi dilakukan dengan mengambil dimensi matriks $50 \times 50$, reduksi dilakukan sehingga matriks mempunyai rank 25 sampai full rank. Elemenelemen matriks dibangkitkan dari Matlab dengan mengambil bilangan random.

Ditampilkan grafik kesalahan relatif

$$
e r r=\frac{\|A-A *\|}{\|A\|}
$$

dengan $A *$ adalah hasil reduksi rank dari $A$, serta nilai singular dari matriks $A, \sigma_{i}$.
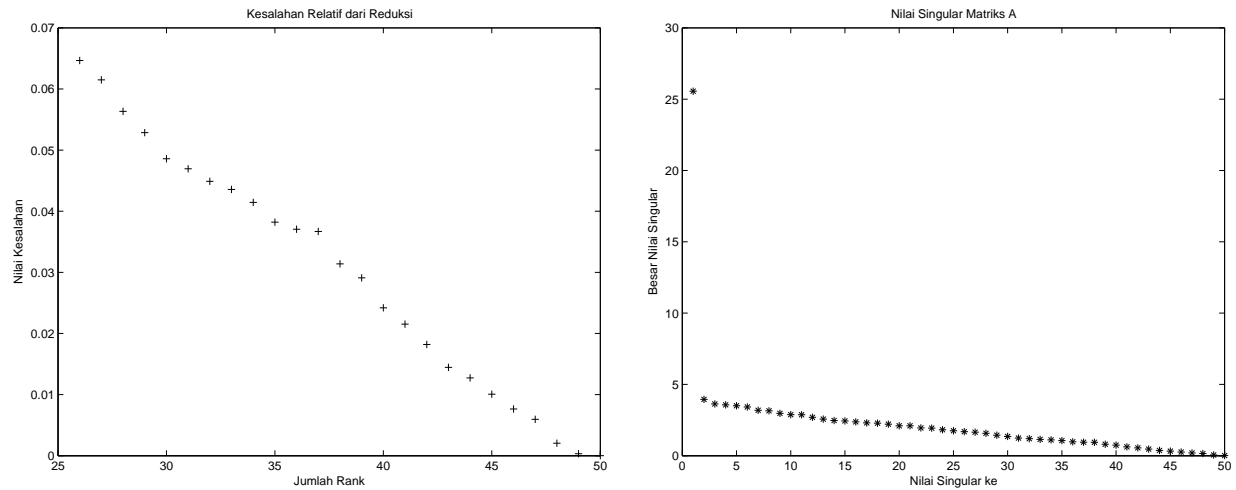

Gambar 1: Kesalahan Relatif Reduksi Gambar 2: Nilai Singular Untuk Full Rank Full Matriks

Matriks

Dengan melakukan beberapa kali simulasi diperoleh pola hubungan antara kesalahan relatif dan reduksi rank untuk masing-masing jenis matriks. Tampak bahwa semakin besar reduksi rank yang dilakukan maka kesalahan relatif matriks semakin besar.

Pada paper ini reduksi rank belum diterapkan untuk menyelesaikan masalah sistem persamaan linear. Untuk menerapkan reduksi rank matriks pada masalah sistem persamaan linear perlu dilakukan langkah-langkah berikut: 

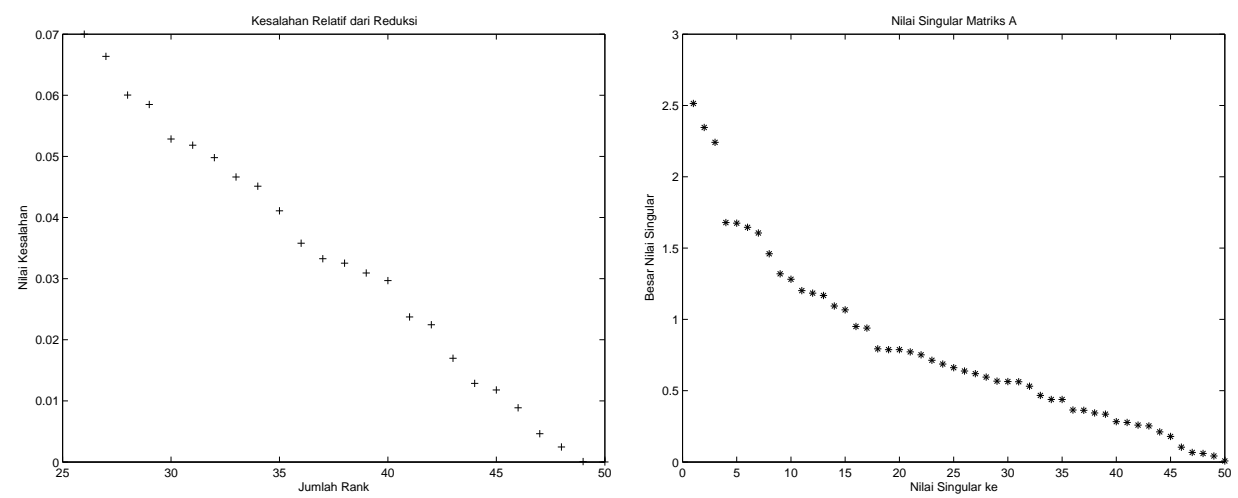

Gambar 3: Kesalahan Relatif Reduksi Gambar 4: Nilai Singular Matriks DiaRank Matriks Diagonal gonal
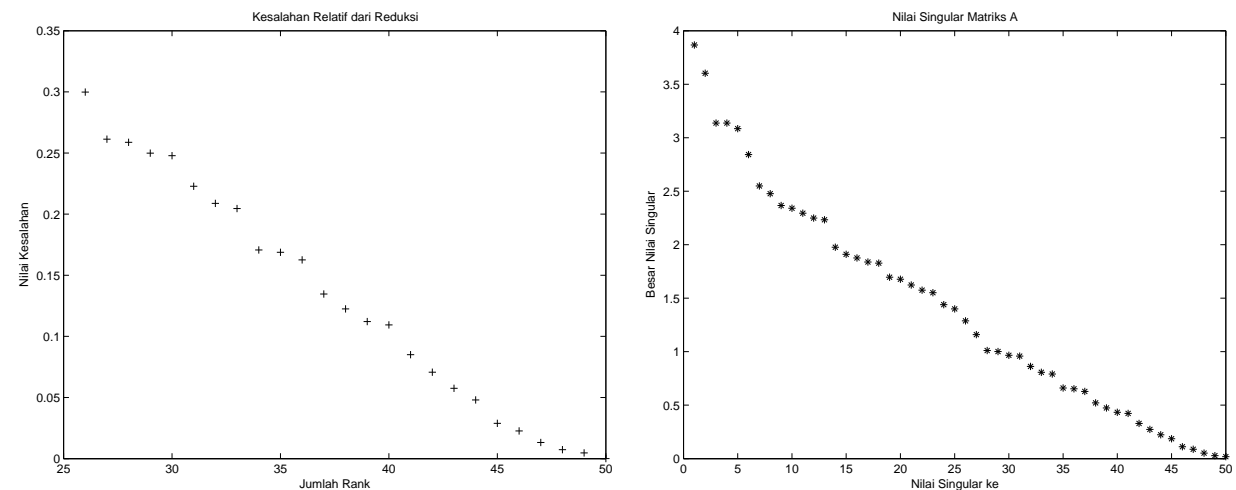

Gambar 5: Kesalahan Relatif Reduksi Gambar 6: Nilai Singular Matriks Trirank Matriks Tridiagonal diagonal

- Misalkan Tentukan $x$ yang merupakan penyelesaian dari $A x=b$.

- Lakukan dekomposisi nilai singular dari $A,[U, D, V]=\operatorname{svd}(A)$

- Misalkan tanpa melakukan reduksi rank maka berlaku $U D V^{T} x=b$ untuk matriks $A$ non singular sehingga diperoleh $x=\left(U D V^{T}\right)^{-1} b$ atau $x=V D^{-1} U^{T} b$, karena $U, V$ merupakan matriks-matriks ortonormal.

- Untuk matriks $A$ yang singular atau beukan matriks bujur sangkar 

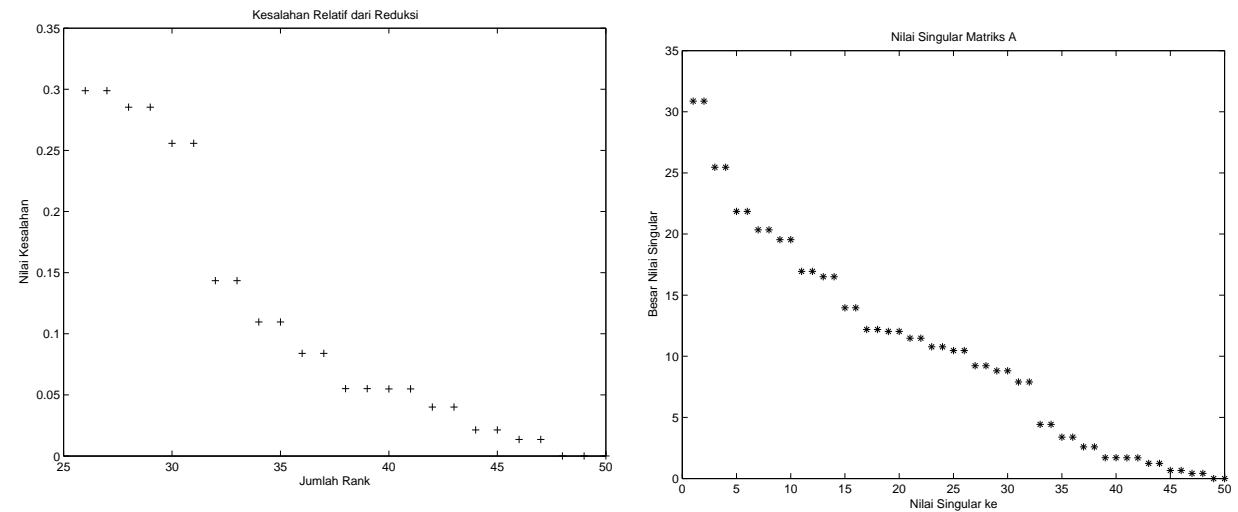

Gambar 7: Kesalahan Relatif Reduksi rank Matriks Tridiagonal elemen Diagonal Nol

Gambar 8: Nilai Singular Matriks Tridiagonal elemen Diagonal Nol
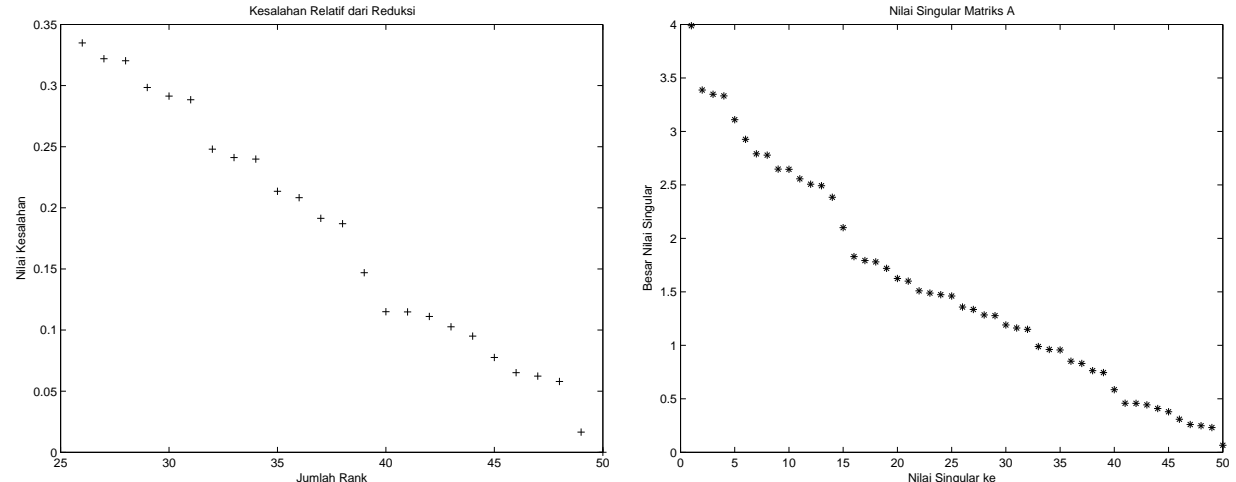

Gambar 9: Kesalahan Relatif Reduksi Gambar 10: Nilai Singular Matriks Trirank Matriks Tridiagonal Simetri diagonal Simetri

maka harus dicari pseudo-invers dari matriks $A$ terlebih dahulu.

- Dengan melakukan reduksi rank $A^{*}=U^{*} D^{*}\left(V^{*}\right)^{T}$ maka harus dicari pseudo-invers dari $A^{*}$ terlebih dahulu sebelum dikalikan dengan $b$. 


\section{Kesimpulan}

Berdasarkan kajian teori dan hasil simulasi diperoleh kesimpulan sebagai berikut:

1. Reduksi Rank dapat dilakukan dengan kesalahan relatif yang kecil jika nilai singular mempunyai loncatan nilai antara $\sigma_{q}$ ke $\sigma_{q+1}$

2. Untuk matriks diagonal reduksi rank akan memberikan kesalahan relatif yang lebih besar

3. Penerapan reduksi rank pada masalah sistem persamaan linear masih diperlukan kajian dan simulasi lebih lanjut.

\section{Pustaka}

[1] Golub, G.H. and Van Loan, C.F.,1989, Matrix Computation,The Johns Hopskins University Press

[2] Apriliani, E.,2001, The Application of the Modified RRSQRT Filter on One Dimensional Shallow Water Problem; Proc ITB,Vol34,no 1. 